\title{
Wohin mit den Plastikstrohhalmen?
}

\author{
Forscher aus Brasilien haben eine neue Anwendung für Plastikhalme gefunden: Sie stellen \\ Fasern aus recycelten Plastikstrohhalmen her, die als Additive für Feuerfestmaterialien \\ eingesetzt werden können. Diese Fasern machen das Trocknen feuerfester Produkte sicherer \\ und schneller.
}

In den vergangenen Jahrzehnten haben die Menschen pro Tag etwa 9 Milliarden PlastikGetränkehalme verbraucht, von denen die meisten zusammen mit jährlich 5 bis 10 Millionen Tonnen anderer Kunststoffabfälle in die Meere gelangten. Da sie schwimmfähig sind, breiten sie sich nach einigen Monaten über die Ozeane aus. Das hat zerstörerische Auswirkungen auf das Wasserleben und daher haben viele Städte ihre Verwendung verboten.

Strohhalme werden typischerweise aus isostatischem Polypropylen (PP) oder Polyethylen hoher Dichte (HDPE) hergestellt, deren Recycling aufgrund der Schwierigkeiten der selektiven Aufnahme und des thermischen Abbaus dieser Polymere bei einem zweiten Verarbeitungszyklus schwierig ist. Folglich können recycelte Strohhalme nicht zur Her- stellung neuer Strohhalme verwendet werden. In einer kürzlich erschienenen Publikation wurde eine neue Verwendungsmöglichkeit für diese Materialien vorgeschlagen.

\section{Fasern erleichtern die} Freisetzung von Wasserdampf Forscher aus Brasilien von der Federal University of São Carlos und der São Carlos School of Engineering verwendeten recycelte Strohhalme, um daraus durch Schmelzspinnen dünne Endlosfasern herzustellen (Bild 1). Diese wurden in $3 \mathrm{~mm}$ große Stücke geschnitten und in eine selbstfließende, feuerfeste, gießfähige Mischung mit hohem Tonerdegehalt gegeben. Nach dem Aushärten und während der ersten Erwärmung der

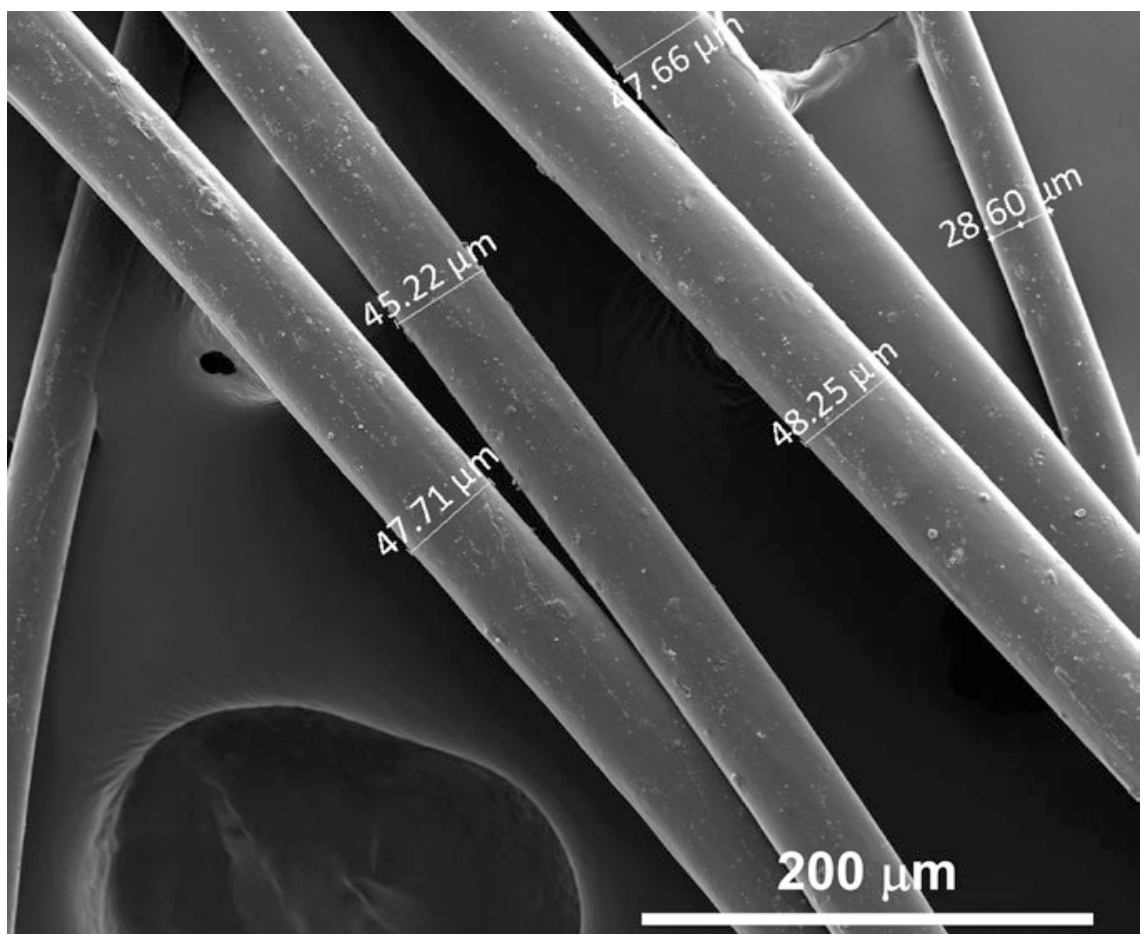

Bild 1 Fasern werden als Additive bei der Herstellung von feuerfesten Produkten verwendet, um explosionsartige Abplatzungen zu verhindern. (C Salomão)

\section{Literaturhinweis}

R. Salomão, V.C. Pandolfelli, “Anti-spalling fibers for refractory castables: A potential application for recycling drinking straws", Ceramics International (In press) (2020). doi.org/10.1016/j.ceramint.2020.02.122

gegossenen Teile schmelzen die recycelten Strohhalmfasern und bilden durchlässige Kanäle in der gesamten Struktur des feuerfesten Materials, wodurch die Freisetzung von Wasserdampf erleichtert wird. Diese Fasern verhindern explosionsartige Abplatzungen, die durch den unter Druck stehenden Wasserdampf verursacht werden, und verringern damit die erforderliche Zeit und den Energieverbrauch für das Aufheizen der feuerfesten Auskleidungen erheblich.

Die recycelten Fasern haben einen deutlich niedrigeren Schmelzpunkt (ca. $141^{\circ} \mathrm{C}$ ) als die konventionellen Fasern $\left(170-180^{\circ} \mathrm{C}\right)$, die hier normalerweise eingesetzt werden. Dadurch können sie den Wasserdampfdruck effizienter reduzieren, was eine sicherere Installation der Feuerfestauskleidung bei geringerem Brennstoffverbrauch und verkürzte Wartungszeiten ermöglicht. Außerdem können sie auch im Baubeton eingesetzt werden, um Explosionen in Brandsituationen nach dem gleichen Prinzip zu verhindern. Da diese Betone in einem viel größeren Volumen als feuerfeste Vergussmassen hergestellt werden, könnten hier zudem auch andere Arten von Kunststoffabfällen zur Herstellung von recycelten Fasern verwendet werden.

Kontakt:

Prof. Dr. Rafael Salomão,

São Carlos School of Engineering (EESC),

University of São Paulo (USP), Brasilien, www.sites.google.com/site/rflslm 